\title{
UTILIZAÇÃO DE LUVAS DE POLIETILENO E CANO LONGO EM PERÍCIAS DE LOCAIS DE CRIME
}

\author{
Guilherme Ribeiro Valle*
Instituto de Criminalística, Polícia Civil de Minas Gerais, Belo Horizonte, MG, Brasil
}

\section{RESUMO}

Este artigo apresenta e discute as vantagens e forma de utilização de luvas de cano longo em polietileno associadas a luvas de procedimento por peritos criminais durante a manipulação de cadáveres e objetos contaminados em perícias de locais de crime. A luva é indicada como uma boa alternativa de equipamento de proteção individual contra risco biológico.

PALAVRAS-CHAVE: Biossegurança. Perícia de locais de crime. Fatores de risco biológico.

\section{THE USE OF POLYETHYLENE LONG SLEEVE GLOVES IN CRIME SCENES}

\begin{abstract}
The advantages and way to use of polyethylene long sleeve gloves associated with procedure gloves by forensic experts during the manipulation of cadaver and contaminated objects in crime scenes are presented and discussed in this article. The gloves are indicated as a good alternative of individual protection equipment against biological risk.
\end{abstract}

KEYWORDS: Biosafety. Crime scene. Biological risk factors. 


\section{INTRODUÇÃO}

Durante a atividade pericial em locais de crime como homicídios, suicídios, cadáveres encontrados em circunstância de morte a esclarecer, acidentes de trânsito e de trabalho, há exposição ocupacional a agentes biológicos de risco pelos profissionais da segurança pública decorrente do manuseio de cadáveres e de seus fluidos corporais potencialmente infectantes como sangue, secreções e excreções, resíduos de massa encefálica e vísceras ${ }^{1,2}$. A Norma Regulamentadora $n^{0} 6$ (NR-6), da Secretaria Especial de Previdência e Trabalho do Ministério da Economia do Brasil, em sua atualização mais recente, datada de 19/10/2020, discrimina os diversos tipos de Equipamentos de Proteção Individual (EPI) para uso no trabalho em geral. Dentre eles, citam-se: luvas, creme protetor, manga, braçadeira e dedeira para a proteção de membros superiores ${ }^{3}$. Embora não haja uma normatização específica para peritos criminais e outros profissionais da segurança pública do Estado de Minas Gerais, mas apenas recomendações não oficiais, o perito designado para cumprir diligência em local de crime pode definir quais EPIs adequados para cada situação. Dentre os mais utilizados, estão as luvas de procedimento descartáveis, jalecos, óculos de proteção e máscaras ${ }^{1,4}$.

Luvas descartáveis de polietileno com cano longo são de uso comum em procedimentos médico-veterinários, com finalidade de se evitar contato dos membros superiores do profissional com tecidos, secreções e excreções animais ${ }^{5}$. 0 polietileno é um polímero plástico de grande maleabilidade, o que lhe confere resistência e maciez ${ }^{6}$. São luvas confortáveis, descartáveis e com várias marcas comercializadas como "luvas de palpação retal" ou "luvas para inseminação artificial" em lojas e fornecedores de produtos veterinários, com custo variando de $\mathrm{R} \$ 0,66$ a $\mathrm{R} \$ 1,70$ por unidade, dependendo da marca e modelo (pesquisa de preços realizada na data de 03/02/2021) ${ }^{7}$.
Este artigo tem como objetivo apresentar esta luva plástica como complementar para uso por peritos criminais e outros profissionais da segurança pública em locais de crime que ofereçam risco biológico.

\section{RELATO}

Há 18 anos, quando nomeado para exercer atividades na área de crimes contra a vida no Instituto de Criminalística da Polícia Civil de Minas Gerais, Brasil (IC/MG), este autor, graduado em Medicina Veterinária e com experiência no uso cotidiano de luvas plásticas descartáveis de cano longo em procedimentos médico-veterinários, vislumbrou vantagens em seu uso durante os procedimentos periciais, especialmente no exame de cadáveres em locais de morte violenta. A prática rotineira dos peritos criminais, à época, era o uso de luvas de procedimento associadas, ou não, a jalecos de tecido de mangas longas, o que protegia as mãos do contato com contaminantes biológicos provenientes de cadáveres, mas insuficientemente os antebraços e braços, uma vez que os jalecos não eram impermeáveis. Atualmente, essas luvas plásticas descartáveis de cano longo, associadas a luvas de procedimento sobrepostas, são de uso rotineiro por vários peritos do IC/MG, no momento das perícias dessa natureza.

A luva plástica de cano longo deve ser calçada e presa à altura do terço superior do braço por meio de uma tira de látex, ou outro meio, de forma que permaneça cobrindo todo o membro superior durante as atividades. Sobre elas, calçam-se luvas de procedimento de látex ou outro material. Após a realização dos exames periciais, retira-se todo o conjunto de forma asséptica e faz-se o descarte adequado. Sua maleabilidade e maciez tornam o uso confortável, e a impermeabilidade promove tranquilidade ao profissional quanto à efetiva proteção de seus membros superiores frente ao contato com sólidos e fluidos potencialmente contaminantes durante os procedimentos periciais (Figura 1).

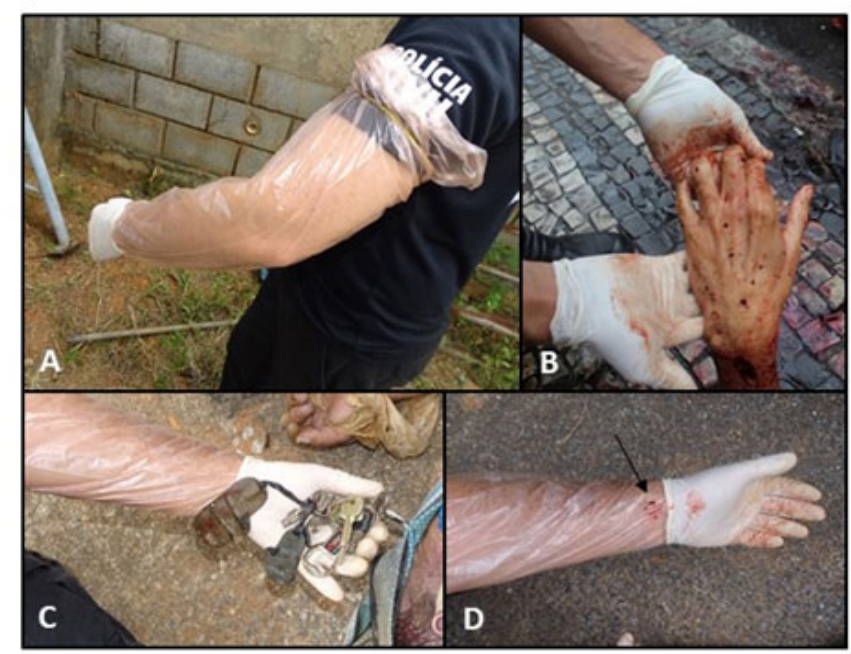

Figura 1: Utilização das luvas de polıetıleno de cano Iongo para exame perıcıal em Iocaıs de crıme: A) Luva calçada, presa no terço superior do braço e luva de procedimento sobreposta; B) Utilização apenas de luvas de procedimento na manipulação de um cadáver e potencial risco de contaminação dos antebraços com material biológico; C) Manipulação de objeto contaminado por sangue e outros fluidos utilizando-se a luva de cano longo associada a luva de procedimento; D) A seta evidencia mancha de sangue transferida para a luva plástica, no antebraço do profissional, fora dos limites de proteção da luva de procedimento. 


\section{DISCUSSÃO}

As luvas de polietileno de mangas longas não fazem parte dos EPIs elencados na NR-6, sendo apenas as luvas de cano curto listadas como EPIs para proteção das mãos contra agentes biológicos ${ }^{3}$. Entretanto, por serem impermeáveis e descartáveis, preferencialmente aquelas com certificado de aprovação (CA) emitido pelo Ministério do Trabalho e Emprego, apresentam vantagens em relação ao uso de jalecos de mangas longas ou macacões, normalmente recomendados para proteção dos antebraços e braços contra riscos biológicos ${ }^{1-4}$. Jalecos e macacões de tecido podem ser impermeáveis ou não, e descartáveis ou não ${ }^{3,4}$. Além disso, apesar de promoverem proteção dos membros superiores contra contaminantes secos e úmidos, podem ser desconfortáveis quando o trabalho se faz sob alta temperatura do ambiente devido à dificuldade de transpiração do profissional, não apenas nos membros superiores e tronco, como também em membros inferiores, no caso dos macacões. Já os jalecos de manga longa em tecido permeável são insuficientes na proteção contra contaminantes úmidos, como sangue, que podem ser absorvidos pelo tecido e ter contato com a pele do profissional. Ademais, se não forem descartáveis, jalecos e macacões demandam higienização após 0 uso ${ }^{3,4}$, o que pode ser um inconveniente na rotina de trabalho desses profissionais que, muitas vezes, atendem diferentes locais de crime em sequência, sem a possibilidade de adequada higienização.

Ressalta-se, também, que o baixo custo das luvas de cano longo em polietileno se resulta em uma boa relação custo-benefício quando de sua aquisição pelas instituições governamentais de atividade pericial.

Portanto, as luvas plásticas de cano longo originalmente desenvolvidas para uso veterinário, apesar de não fazerem parte do rol oficial de EPIs para controle de infecção por agentes contaminantes biológicos no trabalho de profissionais da segurança pública, são uma boa opção de proteção durante atividades pe- riciais envolvendo manipulação de cadáveres, seus derivados e objetos potencialmente contaminados em locais de crime.

\section{REFERÊNCIAS}

1. Yamahira J. Implementação de ações em Segurança do TrabaIho em atividades da perícia criminal no núcleo de criminalística de Três Lagoas/MS [internet] 2015 [acesso em 01 fev 2021]. Disponível em: https://jus.com.br/artigos/36257/implementacao-de-acoes -em-seguranca-do-trabalho-em-atividades-da-pericia-criminal-nonucleo-de-criminalistica-de-tres-lagoas-ms

2. Brasil. Exposição a materiais biológicos - Saúde do trabalhador - Protocolos de complexidade diferenciada 3. Ministério da Saúde - Secretaria de Atenção à Saúde - Departamento de Ações Programáticas Estratégicas. 76p. [internet] 2006 [acesso em 28 abr 2021]. Disponível em: http://bvsms.saude.gov.br/bvs/publicacoes/protocolo_expos_mat_biologicos.pdf

3. Brasil. NR 6 - Equipamento de proteção individual - EPI. Ministério da Economia - Secretaria Especial de Previdência e Trabalho. [internet] 2020 [acesso em 01 fev 2021]. Disponível em: https:// www.gov.br/trabalho/pt-br/inspecao/seguranca-e-saude-no-trabaIho/normas-regulamentadoras/nr-06.pdf/view

4. Moraes TR. O perito criminal e o risco biológico, uma parceria permanente e constante [internet] 2020 [acesso em 01 fev 2021]. Disponível em: https://institutoexito.net.br/artigo/o-perito-criminal-e -o-risco-biologico-uma-parceria-permanente-e-constante

5. Dirksen G. Sistema digestivo. In: Dirksen G, Grunder H-D, Stober M. Exame clínico dos bovinos. 3.ed. Rio de Janeiro: Guanabara Koogan; 1993. cap. 7. p.166-228.

6. Coutinho FMB, Mello IL, Maria LCS. Polietileno: principais tipos, propriedades e aplicações. Polímeros Ciênc. Tecnol. 2003; 13(1):1-13.

7. Mercado Livre [internet] [acesso em 03 de fev 2021]. Disponível em: https://www.mercadolivre.com.br 